\title{
Prediction Model of Deep Learning for Ambulance Transports in Kesennuma City by Meteorological
} Data

\author{
Ohmi Watanabe' \\ Norio Narita ${ }^{2}$ \\ Masahito Katsuki $\mathbb{D}^{2}$ \\ Naoya Ishida' \\ Siqi Cai ${ }^{1}$ \\ Hiroshi Otomo ${ }^{3}$ \\ Kenichi Yokota ${ }^{3}$ \\ 'Kesennuma City Hospital, Kesennuma, \\ Miyagi 988-0I8I, Japan; ${ }^{2}$ Department of \\ Neurosurgery, Kesennuma City Hospital, \\ Kesennuma, Miyagi 988-0I8I, Japan; \\ ${ }^{3}$ Department of Surgery, Kesennuma City \\ Hospital, Kesennuma, Miyagi 988-0I8I, \\ Japan
}

This article was published in the following Dove Press journal: Open Access Emergency Medicine

Purpose: With the aging population in Japan, the prediction of ambulance transports is needed to save the limited medical resources. Some meteorological factors were risks of ambulance transports, but it is difficult to predict in a classically statistical way because Japan has 4 seasons. We tried to make prediction models for ambulance transports using the deep learning (DL) framework, Prediction One (Sony Network Communications Inc., Tokyo, Japan), with the meteorological and calendarial variables.

Materials and Methods: We retrospectively investigated the daily ambulance transports and meteorological data between 2017 and 2019. First, to confirm their association, we performed classically statistical analysis. Second, to test the DL framework's utility for ambulance transports prediction, we made 3 prediction models for daily ambulance transports (total daily ambulance transports more than 5 or not, cardiopulmonary arrest (CPA), and trauma) using meteorological and calendarial factors and evaluated their accuracies by internal cross-validation.

Results: During the 1095 days of 3 years, the total ambulance transports were 5948, including 240 CPAs and 337 traumas. Cardiogenic CPA accounted for $72.3 \%$, according to the Utstein classification. The relation between ambulance transports and meteorological parameters by polynomial curves were statistically obtained, but their $\mathrm{r}^{2} \mathrm{~s}$ were small. On the other hand, all DL-based prediction models obtained satisfactory accuracies in the internal cross-validation. The areas under the curves obtained from each model were all over 0.947 . Conclusion: We could statistically make polynomial curves between the meteorological variables and the number of ambulance transport. We also preliminarily made DL-based prediction models. The DL-based prediction for daily ambulance transports would be used in the future, leading to solving the lack of medical resources in Japan.

Keywords: ambulance transport, cardiopulmonary arrest, deep learning, meteorological factors, trauma

\section{Introduction}

With the aging population in Japan, ambulance transport increases, which exhausts the health care system. ${ }^{1}$ Therefore, the prediction of the ambulance transports is needed to save the limited medical resources. In Japan, weather, or meteorological factors are related to ambulance dispatches, the number of deaths, and traumas. ${ }^{2-4}$ Also, the total numbers of deaths have a relationship with air temperatures, ${ }^{5-8}$ and winter also relates to trauma like fractures ${ }^{9}$ and motor vehicle accidents. ${ }^{10}$

However, there are 4 seasons in Japan with meteorological flections. The risk factors for these diseases may vary depending on the seasons. ${ }^{11-13}$ Therefore, previous studies
Correspondence: Norio Narita Department of Neurosurgery, Kesennuma City Hospital, 8-2, Akaiwa-Suginosawa, Kesennuma, Miyagi, Japan, 988-018I

$\mathrm{Tel} / \mathrm{Fax}+8 \mathrm{I}-226-22-7100$

Email nnarita@mbr.nifty.com 
on the relationship between the weather and ambulance dispatches have been limited to univariate analysis using quadratic functions ${ }^{6,7}$ or multivariate analysis using regression formula with separation by seasons or months focusing on specific diseases. ${ }^{2-4,10,11}$ Furthermore, some studies focused on the "chronological" changes of the meteorological factors in the former days because physical responses to environmental changes may be delayed. ${ }^{11,14}$ Therefore, due to Japan's 4 seasons and delayed physical responses to environmental changes, statistically creating prediction models for the ambulance dispatches, incidences of deaths, or traumas are difficult.

Recently, deep learning (DL) technology is attractive. DL can treat chronological data like the date that is difficult to be processed statistically. Therefore, we herein produced the prediction models for ambulance transports, incidences of cardiopulmonary arrests (CPAs) or traumas using the DL framework, Prediction One (Sony Network Communications Inc., Tokyo, Japan) ${ }^{15}$ with meteorological and calendarial data, and tested the utility of the DL-based models.

\section{Materials and Methods}

We performed 2 studies; First, to confirm the association between ambulance transports and meteorological data, we performed a retrospective and statistical analysis similar to the previous reports. ${ }^{6,7}$ Second, we made prediction models for daily ambulance transports using meteorological and calendarial factors and evaluated their accuracies to test the utility of the DL-based models.

\section{Study Area}

Japan has four distinct seasons: spring, summer, autumn, and winter. Miyagi prefecture, where Kesennuma City Hospital ${ }^{16}$ is located, is in the Northeastern part (North latitude 38.5 degrees and East longitude 141.3 degrees) in a Dfa zone based on Köppen-Geiger climate classification (Figure 1A). ${ }^{17}$ Kesennuma City Hospital (red triangle in Figure 1B) is the only acute care hospital in this medical area with a background population of about 100,000 people (light green area in Figure 1B). Our hospital has 340 beds. We do not have any intensive care units, emergency departments, nor emergency physicians. Doctors from all departments work by turns in the emergency room. After diagnosis, appropriate doctors nextly treat patients. We perform intensive care in the general ward of each department. If the patients need further advanced medical care, they are transported to Tohoku University Hospital in Sendai by helicopter.

\section{Ambulance Transports}

Daily incidence of total ambulance transports, CPAs, and traumas to Kesennuma City Hospital in the Kesennuma
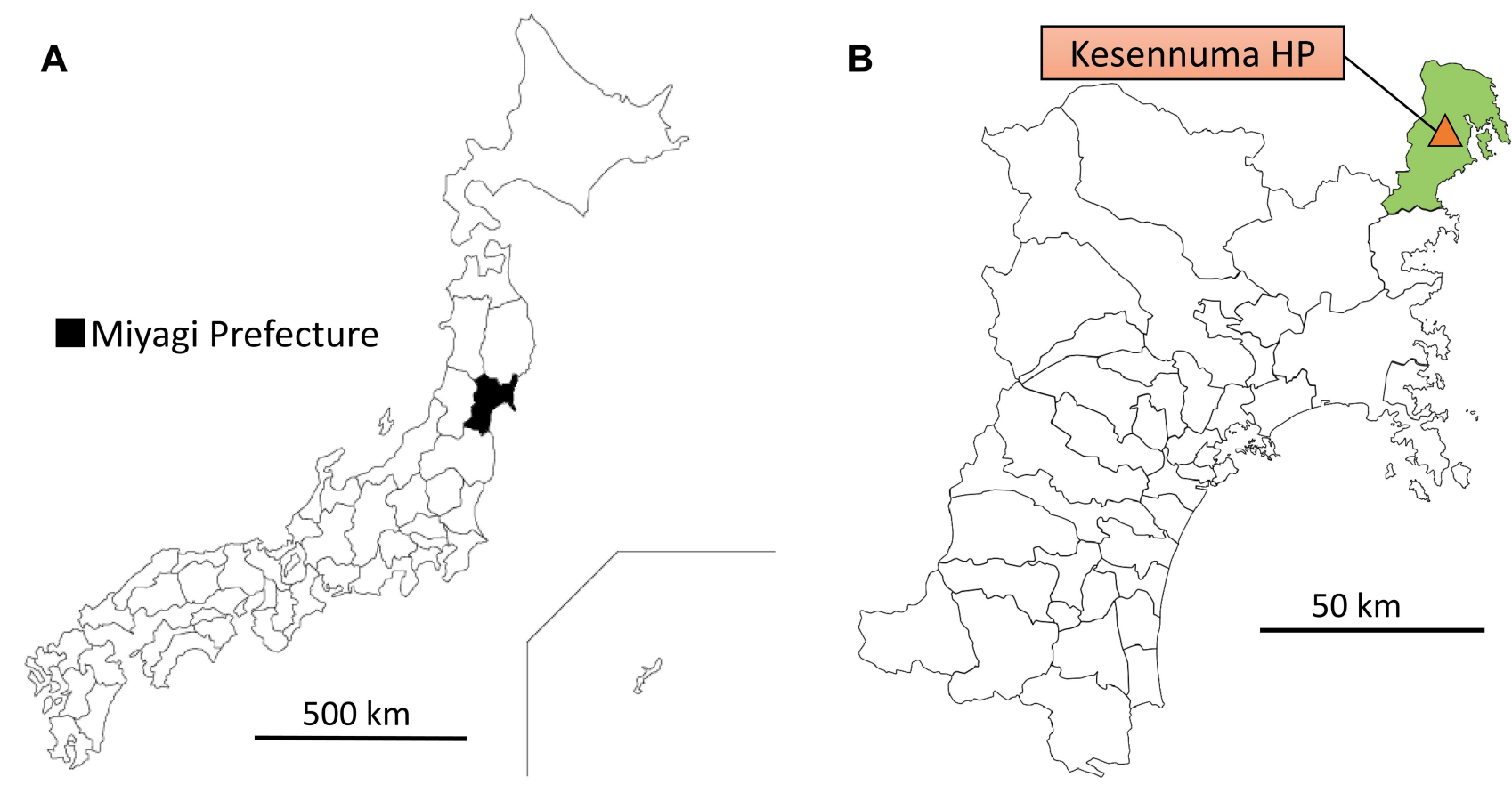

Figure I (A) Map of Japan. Miyagi prefecture, where Kesennuma City Hospital (HP) locates, is in the northeastern part of Japan (colored black). (B) Map of Miyagi prefecture. The Kesennuma area, with a background population of about 100,000 people, is colored light green. The red triangle is Kesennuma City HP, where this study was performed. 
medical area were obtained from Fire Department Service in Kesennuma from 2017 to 2019. The causes of CPA were classified into cardiogenic and non-cardiogenic causes by Utstein classification. ${ }^{18}$ Trauma includes highenergy traumas and mild ones transported by ambulance, like traffic accidents or falls.

\section{Meteorological and Calendarial Data}

Meteorological data included daily mean ambient temperature (Tmean, ${ }^{\circ} \mathrm{C}$ ), highest ambient temperature (Tmax, ${ }^{\circ}$ C), lowest ambient temperature (Tmin, ${ }^{\circ} \mathrm{C}$ ), the difference between the highest and lowest ambient temperature (Tmax-min, ${ }^{\circ} \mathrm{C}$ ), mean atmospheric pressure $(\mathrm{Pa}, \mathrm{hPa}$ ), daily mean vapor pressure $(\mathrm{hPa})$, mean wind speed $(\mathrm{m} / \mathrm{s})$, amount of the rainfall $(\mathrm{mm})$ or snowfall $(\mathrm{mm})$, sunlight hours (hr), and mean relative humidity ( $\mathrm{RH}, \%$ ) of the 24$\mathrm{hr}$ calendar day period (0:00AM-11:59PM) on the day and the last 7 days of the ambulance transport, which were obtained from the local meteorological observatories. ${ }^{19}$ The thermo-hydrological index $\left(\mathrm{THI},{ }^{\circ} \mathrm{C}\right)$ was calculated using the formula; THI $=$ Tmean $-0.55 \times(1-0.01 \times \mathrm{RH})$ $\mathrm{x}$ (Tmean - 14.5]) as reported previously. ${ }^{20}$ This index is an established appropriate measure for evaluating the effect of air temperature on health outcomes because it takes into account mean air temperature after controlling for the effect of relative humidity. The distance from our hospital to the meteorological observatory was $3.8 \mathrm{~km}$.

The daily changes of some meteorological factors, including Tmean, Tmax, Tmin, Tmax-min, Pa, RH, and THI, for the last 7 days from the onset were calculated as follows; Day by day difference, difference every 2 days, 3 days, 4 days, 5 days, and 6 days. We also investigated the date, day of the week, and national holidays.

\section{Making Prediction Models}

We used Prediction One to make the prediction models for daily ambulance transport using all variables described above. We made prediction models by the dataset between 2017 and 2019, and evaluated their accuracies by internal cross-validation. Prediction One read the dataset and automatically and randomly divided them into half as internal training and cross-validation datasets. It adjusted and optimized the variables that are easy to process statistically and mathematically and select an appropriate algorithm with ensemble learning. Notably, the date and day of the week are processed as a trigonometric function to reflect the circular characteristics. Prediction One made the best prediction model with internal cross-validation. The details are trade secrets and could not be provided.

We made 3 prediction models; one for total ambulance transport more than 5 (median) or not, one for daily CPA transport (present or absent), and the other for daily trauma transport (present or absent). The area under the curves (AUC) of the receiver operating characteristic curve (ROC) of each model was statistically calculated, and we evaluated the models' accuracy.

\section{Statistical Analysis}

Linear, quadratic, or cubic polynomial curve fitting was applied to the link between ambulance transports and climate parameters using SPSS software version 24.0.0. (IBM, New York, USA) with command "CURVE FITTING." The curve with the largest determination coefficient $\left(r^{2}\right)$ and a $p$ value of less than 0.05 was adopted. Mann-Whitney $U$-test and Kruskal-Wallis test examined the association between day of the week and the outcomes. The AUCs of ROC obtained from each model made by Prediction One using internal cross-validation were calculated. These statistical analyses were performed using all the 3-year database. A two-tailed $p<0.05$ was considered statistically significant.

\section{Ethics}

The protocol for this research project has been approved by a suitably constituted Ethics Committee of the institution and it conforms to the provisions of the Declaration of Helsinki; Kesennuma City Hospital Research Ethics Committee, Approval No. KHEC-6. We could not gain written informed consent for this study from all of the patients, because the data from the Fire Department Service in Kesennuma was anonymized. Also, this is an anonymized observational study, and informed consent was waived.

\section{Results}

During the 1095 days of 3 years, the monthly incidence of the 5948 total ambulance transports, including 240 CPAs and 337 traumas, and monthly meteorological factors are summarized in Table 1. The median (interquartile range) age was 76 (60-85) years old. We included 2716 women and 3232 men.

\section{Meteorological and Calendarial Factors and Ambulance Transports}

We estimated the relation between ambulance transports and meteorological parameters by linear, quadratic, or cubic polynomial curves (Table 2). Total ambulance transports 
Table I Number of Ambulance Transports and Meteorological Factors

\begin{tabular}{|c|c|c|c|c|c|c|c|}
\hline \multirow[t]{2}{*}{ Year } & \multirow[t]{2}{*}{ Month } & \multicolumn{3}{|c|}{ Ambulance Transport (Number) } & \multicolumn{3}{|c|}{$\begin{array}{l}\text { Meteorological Factors } \\
\text { (Monthly Average) }\end{array}$} \\
\hline & & Total & CPA & Trauma & Tmean $\left({ }^{\circ} \mathrm{C}\right)$ & $\mathbf{P a}(\mathrm{hPa})$ & RH (\%) \\
\hline \multirow[t]{12}{*}{2017} & Jan & 188 & 10 & 4 & 1.3 & 1009.5 & 64 \\
\hline & Feb & 159 & 7 & 3 & 2.3 & 1007.8 & 62 \\
\hline & Mar & 154 & 1 & II & 4.0 & 1009.6 & 64 \\
\hline & Apr & 150 & 4 & 7 & 9.9 & 1007.9 & 66 \\
\hline & May & 168 & 10 & 7 & 15.7 & 1008.0 & 70 \\
\hline & Jun & 164 & 5 & 10 & 17.0 & 1004.4 & 79 \\
\hline & Jul & 151 & 4 & 15 & 23.6 & 1004.4 & 82 \\
\hline & Aug & 153 & 2 & 7 & 21.8 & 1004.8 & 89 \\
\hline & Sep & 178 & 5 & 12 & 19.4 & 1007.5 & 79 \\
\hline & Oct & 134 & 4 & 6 & 13.7 & 1014.7 & 80 \\
\hline & Nov & 161 & 9 & 9 & 8.1 & 1012.3 & 68 \\
\hline & Dec & 172 & 5 & 14 & 2.5 & 1010.3 & 66 \\
\hline \multicolumn{2}{|c|}{ Total of 2017} & 1932 & 66 & 105 & 11.6 & 1008.4 & 72 \\
\hline \multirow[t]{12}{*}{2018} & Jan & 189 & 15 & II & 0.9 & 1008.2 & 61 \\
\hline & Feb & 152 & 11 & 6 & 0.4 & 1011.5 & 60 \\
\hline & Mar & 148 & 3 & 13 & 6.8 & 1012.5 & 60 \\
\hline & Apr & 150 & 4 & 9 & 11.4 & 1009.6 & 66 \\
\hline & May & 165 & 5 & 14 & 15.4 & 1007.0 & 71 \\
\hline & Jun & 129 & 4 & 7 & 18.5 & 1005.3 & 81 \\
\hline & Jul & 159 & 0 & 7 & 23.6 & 1006.7 & 87 \\
\hline & Aug & 196 & 7 & 12 & 23.6 & 1005.1 & 83 \\
\hline & Sep & 146 & 7 & 4 & 19.9 & 1010.1 & 84 \\
\hline & Oct & 159 & 7 & 9 & 15.2 & 1011.7 & 77 \\
\hline & Nov & 147 & 5 & 6 & 9.3 & 1015.7 & 71 \\
\hline & Dec & 204 & 11 & 15 & 3.5 & 1013.2 & 66 \\
\hline \multicolumn{2}{|c|}{ Total of 2018} & 1944 & 79 & 113 & 12.4 & 1009.7 & 72 \\
\hline \multirow[t]{12}{*}{2019} & Jan & 179 & 13 & 6 & 1.3 & 1010.2 & 61 \\
\hline & Feb & 130 & 7 & 3 & 2.0 & 1012.9 & 61 \\
\hline & Mar & 151 & 9 & 6 & 5.3 & 1008.3 & 63 \\
\hline & Apr & 148 & 7 & 10 & 8.9 & 1008.7 & 66 \\
\hline & May & 179 & 6 & 10 & 16 & 1004.0 & 67 \\
\hline & Jun & 158 & 5 & 10 & 17.8 & 1006.2 & 83 \\
\hline & Jul & 168 & 8 & 13 & 21.7 & 1004.9 & 83 \\
\hline & Aug & 201 & 5 & 7 & 24.8 & 1011.5 & 83 \\
\hline & Sep & 185 & 2 & 16 & 21.1 & 1013.1 & 78 \\
\hline & Oct & 190 & 11 & II & 15.8 & 1013.1 & 80 \\
\hline & Nov & 200 & 9 & 18 & 8.6 & 1013.6 & 66 \\
\hline & Dec & 183 & 13 & 9 & 4.1 & 1014.4 & 68 \\
\hline \multicolumn{2}{|c|}{ Total of 2019} & 2072 & 95 & 119 & 12.2 & 1010.1 & 72 \\
\hline \multicolumn{2}{|c|}{ Total of 3 years } & 5948 & 240 & 337 & 12.4 & 1009.4 & 72 \\
\hline
\end{tabular}

Abbreviations: CPA, cardiopulmonary arrest; $\mathrm{Pa}$, mean atmospheric pressure; $\mathrm{RH}$, mean relative humidity; Tmean, mean ambient temperature.

were weakly associated with Tmean, Tmax, Tmin, Tmaxmin, daily mean vapor pressure, mean wind speed, $\mathrm{RH}$, and THI. Tmax had the biggest $\mathrm{r}^{2}$ of 0.019 with $\mathrm{p}<0.001$.
Ambulance transports for CPA were weakly associated with Tmean, Tmax, Tmin, Pa, daily mean vapor pressure, sunlight hours, RH, and THI. Tmean and Tmin had the biggest $r^{2} \mathrm{~s}$ of 
Table 2 Approximation by Linear, Quadratic, or Cubic Polynomial Curve Between the Number of Ambulance Transports and Meteorological Factors in the Kesennuma Area

\begin{tabular}{|c|c|c|c|}
\hline Variables (X) & $r^{2}$ & p value & $\begin{array}{l}\text { Polynomial Curve }^{\dagger} \\
\text { (Y: Each Outcome, X: Climate Parameters) }\end{array}$ \\
\hline \multicolumn{4}{|l|}{ Total ambulance transport $(\mathrm{Y})$} \\
\hline Tmean $\left({ }^{\circ} \mathrm{C}\right)$ & 0.018 & $<0.00 I^{*}$ & $Y=0.005 X^{2}-0.131 X+5.872$ \\
\hline $\operatorname{Tmax}\left({ }^{\circ} \mathrm{C}\right)$ & 0.019 & $<0.001 *$ & $Y=0.005 X^{2}-0.152 X+5.418$ \\
\hline $\operatorname{Tmin}\left({ }^{\circ} \mathrm{C}\right)$ & 0.014 & $0.001^{*}$ & $Y=0.004 X^{2}-0.083 X+5.479$ \\
\hline $\operatorname{Tmax}-\min \left({ }^{\circ} \mathrm{C}\right)$ & 0.007 & $0.045^{*}$ & $Y=0.003 X^{3}-0.082 X^{2}+0.761 X+3.331$ \\
\hline $\mathrm{Pa}(\mathrm{hPa})$ & 0.001 & 0.376 & $Y=-0.010 X+15.362$ \\
\hline Daily mean vapor pressure $(\mathrm{hPa})$ & 0.007 & $0.024 *$ & $Y=0.004 X^{2}-0.111 X+5.974$ \\
\hline Mean wind speed $(\mathrm{m} / \mathrm{s})$ & 0.009 & $0.016^{*}$ & $Y=0.046 X^{3}-0.564 X^{2}+2.158 X+2.939$ \\
\hline Daily amount of the rainfall (mm) & 0.002 & 0.270 & $Y=0.0002 X^{2}-0.021 X+5.475$ \\
\hline Daily amount of the snowfall (mm) & $<0.001$ & 0.943 & $Y=-0.013 X^{2}+0.077 X+5.431$ \\
\hline Sunlight hours (hr) & 0.005 & 0.057 & $Y=-0.010 X^{2}+0.140 X+5.141$ \\
\hline $\mathrm{RH}(\%)$ & 0.009 & $0.006 *$ & $Y=-0.001 X^{2}-0.148 X+0.582$ \\
\hline $\mathrm{THI}\left({ }^{\circ} \mathrm{C}\right)$ & 0.016 & $<0.001 *$ & $Y=0.007 X^{2}-0.190 X+6.353$ \\
\hline \multicolumn{4}{|c|}{ Ambulance transport due to CPA $(Y)$} \\
\hline Tmean $\left({ }^{\circ} \mathrm{C}\right)$ & 0.021 & $<0.00 I^{*}$ & $Y=0.0004 X^{2}-0.019 X+0.306$ \\
\hline $\operatorname{Tmax}\left({ }^{\circ} \mathrm{C}\right)$ & 0.020 & $<0.00 I^{*}$ & $Y=0.0004 X^{2}-0.020 X+0.410$ \\
\hline $\operatorname{Tmin}\left({ }^{\circ} \mathrm{C}\right)$ & 0.021 & $<0.00 I^{*}$ & $Y=0.0004 X^{2}-0.013 X+0.276$ \\
\hline $\operatorname{Tmax}-\min \left({ }^{\circ} \mathrm{C}\right)$ & 0.001 & 0.574 & $Y=-0.001 X^{2}-0.014 X+0.173$ \\
\hline $\mathrm{Pa}(\mathrm{hPa})$ & 0.005 & $0.019 *$ & $Y=0.005 X-4.813$ \\
\hline Daily mean vapor pressure $(\mathrm{hPa})$ & 0.015 & $0.001 *$ & $Y=0.003 X^{2}-0.017 X+0.353$ \\
\hline Mean wind speed $(\mathrm{m} / \mathrm{s})$ & 0.001 & 0.255 & $Y=0.016 X+0.176$ \\
\hline Daily amount of the rainfall (mm) & 0.001 & 0.418 & $Y=-0.001 X+0.223$ \\
\hline Daily amount of the snowfall (mm) & 0.001 & 0.982 & $Y=0.001 X^{2}-0.011 X+0.220$ \\
\hline Sunlight hours (hr) & 0.007 & $0.019 *$ & $Y=-0.003 X^{2}+0.034 X+0.164$ \\
\hline $\mathrm{RH}(\%)$ & 0.004 & $0.039 *$ & $Y=-0.002 X+0.370$ \\
\hline $\mathrm{THI}\left({ }^{\circ} \mathrm{C}\right)$ & 0.019 & $<0.00 I^{*}$ & $Y=0.001 X^{2}-0.025 X+0.408$ \\
\hline \multicolumn{4}{|c|}{ Ambulance transport due to trauma $(Y)$} \\
\hline Tmean $\left({ }^{\circ} \mathrm{C}\right)$ & 0.004 & 0.147 & $Y=-0.0004 X^{2}+0.013 X+0.244$ \\
\hline $\operatorname{Tmax}\left({ }^{\circ} \mathrm{C}\right)$ & 0.004 & 0.095 & $Y=-0.0003 X^{2}+0.015 X+0.188$ \\
\hline $\operatorname{Tmin}\left({ }^{\circ} \mathrm{C}\right)$ & 0.003 & 0.250 & $Y=-0.0003 X^{2}+0.008 X+0.292$ \\
\hline $\operatorname{Tmax}-\min \left({ }^{\circ} \mathrm{C}\right)$ & 0.002 & 0.154 & $Y=0.008 X+0.243$ \\
\hline $\mathrm{Pa}(\mathrm{hPa})$ & $<0.001$ & 0.892 & $Y=0.0003 X-0.043$ \\
\hline Daily mean vapor pressure $(\mathrm{hPa})$ & 0.003 & 0.164 & $Y=-0.001 X^{2}+0.018 X+0.204$ \\
\hline Mean wind speed $(\mathrm{m} / \mathrm{s})$ & 0.002 & 0.410 & $Y=0.003 X^{2}-0.017 X+0.353$ \\
\hline Daily amount of the rainfall $(\mathrm{mm})$ & $<0.001$ & 0.764 & $Y=0.00003 X^{2}-0.002 X+0.312$ \\
\hline Daily amount of the snowfall (mm) & $<0.001$ & 0.993 & $Y=-0.001 X^{2}+0.007 X+0.308$ \\
\hline Sunlight hours (hr) & 0.008 & $0.031^{*}$ & $Y=0.001 X^{3}-0.018 X^{2}+0.092 X+0.227$ \\
\hline $\mathrm{RH}(\%)$ & 0.003 & 0.191 & $Y=-0.0002 X^{2}+0.022 X-0.445$ \\
\hline $\mathrm{THI}\left({ }^{\circ} \mathrm{C}\right)$ & 0.003 & 0.201 & $Y=-0.001 X^{2}+0.017 X+0.204$ \\
\hline
\end{tabular}

Notes: $*_{p}<0.05$ for the calculated polynomial curve; flinear, quadratic, or cubic polynomial curve between the number of ambulance transports and meteorological factors were calculated by SPSS software.

Abbreviations: CPA, cardiopulmonary arrest; Pa, mean atmospheric pressure; $r^{2}$, determination coefficient; $\mathrm{RH}$, mean relative humidity; THI, thermo-hydrological index; Tmax, daily highest ambient temperature; Tmax-min, daily difference between the highest and lowest ambient temperature Tmean; mean ambient temperature; Tmin, daily lowest ambient temperature.

0.021 with $\mathrm{p}<0.001$. Ambulance transports for trauma were weakly associated with sunlight hours with $\mathrm{r}^{2}$ of 0.008 with $\mathrm{p}=0.031$ (Table 2).
We also investigated the association between the day of the week, national holidays, and ambulance transports, but the Mann-Whitney $U$-test and Kruskal- 
Table 3 Day of the Week and Numbers of Ambulance Transports

\begin{tabular}{|l|l|l|l|l|}
\hline $\begin{array}{l}\text { Day of the } \\
\text { Week }^{\dagger}\end{array}$ & $\begin{array}{l}\text { Number } \\
\text { of the } \\
\text { Days }\end{array}$ & $\begin{array}{l}\text { Total } \\
\text { Ambulance } \\
\text { Transport }\end{array}$ & CPA & Trauma \\
\hline Monday & 157 & 902 & 37 & 51 \\
Tuesday & 157 & 814 & 27 & 48 \\
Wednesday & 156 & 828 & 34 & 45 \\
Thursday & 156 & 832 & 35 & 42 \\
Friday & 156 & 865 & 33 & 41 \\
Saturday & 156 & 838 & 38 & 55 \\
Sunday & 156 & 869 & 36 & 55 \\
National holiday & $55(4.6 \%)$ & 319 & 11 & 24 \\
\hline Total & 1095 & $\mathbf{5 9 4 8}$ & $\mathbf{2 4 0}$ & $\mathbf{3 3 7}$ \\
\hline
\end{tabular}

Notes: †Mann-Whitney U-test and Kruskal-Wallis test did not show a significant difference depending on the day of the week nor national holidays (all $p>0.05$ ).

Abbreviation: CPA, cardiopulmonary arrest.

Wallis test did not reveal a significant difference depending on the day of the week nor national holidays (Table 3).

\section{CPA Classified by Utstein Classification}

Emergency services classified CPA patients transported by ambulance as cardiogenic or non-cardiogenic according to the Utstein classification. ${ }^{18}$ Cardiogenic CPA accounted for $72.3 \%$ in the three years from 2017 to 2019 .

\section{DL-Based Models for Total Daily Ambulance Transport}

The model for total daily ambulance transport more than 5 (median) or not has an AUC of $0.972(95 \%$ confidence interval (95\% CI) 0.960-0.984). Its sensitivity and specificity were 0.937 and 0.935 (Figure 2A). The model for daily CPA transport (present or absent) has an AUC of 0.988 (95\% CI 0.975-1.000). Its sensitivity and specificity were 0.958 and 0.972 (Figure 2B). The model for daily trauma transport (present or absent) has an AUC of 0.947 (95\% CI 0.927-0.968). Its sensitivity and specificity were 0.899 and 0.892 (Figure 2C).

\section{7-2019 Internal cross-validation}

A

Total daily ambulance transport more than 5 (median) or not AUC: $0.972(95 \% \mathrm{Cl} 0.960-0.984)$ Sensitivity: 0.937 Specificity: 0.935

B

\section{Daily CPA transport} (present or absent)

AUC: 0.988 (95\% Cl 0.975-1.000)

Sensitivity: 0.958

Specificity: 0.972

C

Daily trauma transport (present or absent)

AUC: 0.947 (95\%Cl 0.927-0.968)

Sensitivity: 0.899

Specificity: 0.892

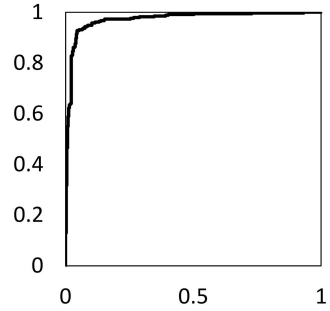

\begin{tabular}{|c|c|c|c|}
\cline { 3 - 4 } \multicolumn{2}{c|}{} & \multicolumn{2}{c|}{ Actual transport } \\
\cline { 3 - 4 } \multicolumn{2}{c|}{} & $6 \leqq$ & $<5$ \\
\hline \multirow{2}{*}{$\begin{array}{l}\text { Predicted } \\
\text { transport }\end{array}$} & $6 \leqq$ & 238 & 19 \\
\cline { 2 - 4 } & $<5$ & 16 & 275 \\
\hline
\end{tabular}

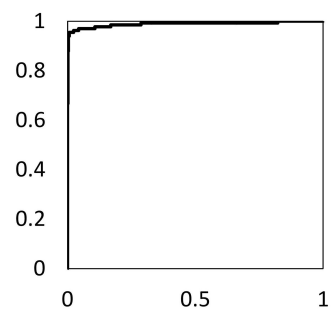

\begin{tabular}{|l|c|c|c|}
\cline { 3 - 4 } \multicolumn{2}{c|}{} & \multicolumn{2}{c|}{ Actual transport } \\
\cline { 3 - 4 } \multicolumn{2}{c|}{} & Present & Absent \\
\hline $\begin{array}{l}\text { Predicted } \\
\text { transport }\end{array}$ & Present & 115 & 12 \\
\cline { 2 - 4 } & Absent & 5 & 416 \\
\hline
\end{tabular}

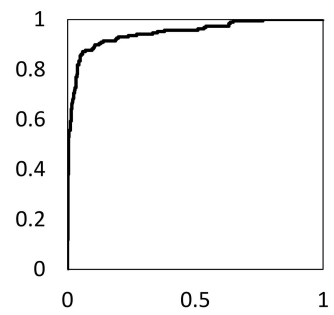

\begin{tabular}{|l|c|c|c|}
\cline { 3 - 4 } \multicolumn{2}{c|}{} & \multicolumn{2}{c|}{ Actual transport } \\
\cline { 3 - 4 } \multicolumn{2}{c|}{} & Present & Absent \\
\hline $\begin{array}{l}\text { Predicted } \\
\text { transport }\end{array}$ & Present & 152 & 41 \\
\cline { 2 - 4 } & Absent & 17 & 338 \\
\hline
\end{tabular}

Figure 2 The area under the curves (AUCs) and calculation tables of each model. (A) The model for total daily ambulance transport more than 5 (median) or not has an AUC of 0.972 ( $95 \%$ confident interval $(95 \% \mathrm{Cl})$ 0.960-0.984). Its sensitivity and specificity were 0.937 and 0.935 . (B) The model for daily CPA transport (present or absent) has an AUC of $0.988(95 \% \mathrm{Cl} 0.975-1.000)$. Its sensitivity and specificity were 0.958 and 0.972 . (C) The model for daily trauma transport (present or absent) has an AUC of 0.947 ( $95 \% \mathrm{Cl} 0.927-0.968)$. Its sensitivity and specificity were 0.899 and 0.892 . 


\section{Discussion}

Our study suggested 2 points; 1 . We performed a retrospective and statistical analysis about the association between ambulance transports and meteorological data. The obtained polynomial curves are statistically significant, but the $r^{2} s$ are very small, suggesting that the statistically polynomial curves could explain only small numbers of transports, and their utilities were low. 2. We made DL-based prediction models for daily ambulance transports using meteorological and calendarial factors and evaluated their accuracies. The AUCs are satisfactory, suggesting the potential of the DL-based ambulance transports prediction.

\section{Problems of the Health Care System in Japan}

Japan adopted a universal healthcare system in 1961 that guarantees patients free access to medical care, ${ }^{1}$ and this free access system is proud of Japan. However, the medical staff has been recently exhausted because 1; some patients with mild illness consult doctors in the off-duty hours as so-called convenience-store consultations. 2; everybody can use an ambulance like a "taxi" without any payment. The dispatches of the ambulance are increasing, although half of the patients' illnesses are mild. ${ }^{21} 3$; medical staff does not receive fair wages. About $7 \%$ of medical doctors were not paid any fairs in $2019 .{ }^{22}$ Furthermore, healthcare costs are increasing over 40 trillion JPY per year, accounting for 35\% of the Japanese annual expenditures. Also, emergency medicine is an unprofitable department, so the number of hospital emergency departments declined in Japan. ${ }^{21}$ Japan is now facing its own unique set of challenges as declining birthrate, aging population, and the medical care system collapse. In order to solve these crises of the health care system in Japan, the consumption tax was increased from $8 \%$ to $10 \%$ in 2019 . Hospitals can also require patients' extra-payment on the emergency department visiting at night and on holidays. However, patients with mild illness using ambulance are still about $50 \%$ over these 10 years. ${ }^{22}$ A previous report in Japan concluded that we must rely on the spontaneous motivation of patients. ${ }^{1}$

\section{The Need for Prediction of Daily Ambulance Transport}

Promoting the appropriate use of ambulances and the emergency department is still difficult in Japan. Therefore, we should deploy limited medical resources in the right amount and at the right time. As we described in the methods section, our hospital does not have emergency doctors nor intensive care units, and there are many such emergency hospitals in Japan's rural area. Doctors who are not specialists in emergency medicine are forced to work in the emergency room by turns. Also, there are fewer comedicals in such rural areas, so we cannot always use many drugs nor perform laboratory and radiological tests. Accurate prediction of the daily ambulance transport is difficult in a classically statistical way, so medical staff must be alert at all times. Management of the drug inventory and the availability of laboratory and radiological testing equipment at night and on holidays are also problems. Therefore, to solve this lack of medical resources in Japan's rural area, we tried to make DL-based prediction models of daily ambulance transports. If we could predict the number of transports, the hospital might increase doctors and co-medicals and let the drugs and testing equipment available only on the predicted busy day; while it might decrease them on the non-busy day.

\section{Previous Studies on Ambulance Transport Prediction}

As we mentioned in the Introduction, many studies in Japan to predict ambulance transport have been done based on meteorological data. However, due to 4 seasons in Japan, the prediction formula is not satisfactory in the classical statistical way. Furthermore, the regional difference and spatial or temporal factors, like economic or social differences, which is challenging to be treated in a statistical way, also affect the ambulance demand's prediction accuracy. ${ }^{23}$ Therefore, similar to our report, several previous studies performed to predict ambulance transport using artificial intelligence, not statistical way.

Setzler et al first reviewed works of literature on the emergency system call prediction. They tried to develop a prediction model using time and postal address by artificial neural network (ANN) technique in Mecklenburg County in $2009 .^{24}$ However, the ANN-based model was inferior to moving average-based formula, which is common in the industry to predict emergency call. After that, Chen used a geographic information system and developed artificial intelligence-based prediction models for emergency calls in Taipei City in $2016 .{ }^{25}$ The best daily mean absolute percentage error was $23.01 \%$. Lin et al performed ambulance demand prediction using leveraging machine learning techniques in Singapore in $2020 .^{23}$ Their study used historical 
demand of the past 30 days as temporal variables, as well as the Census of Population is also included as spatial and demographic variables. They achieved a good prediction with around 25\% accuracy. As pre-hospital care, there are several reports on prediction models "where and when" ambulances will be needed, from a whole social perspective. However, as far as we know, there is no research on developing DL-based models predicting "whether patients are brought to a hospital or not," from the medical staff's perspective. This is the first attempt to make a DL-based prediction model from the hospital and the medical staff's perspective, and this is the unique point of this study.

\section{Future Outlook}

Simple and easy DL frameworks are being developed, so we should be interested in using it to benefit medical staff and patients. ${ }^{26,27}$ Even though our study used a small dataset in our small hospital, we could make satisfactory DL-based prediction models using such a simple DL framework. Nowadays, smartphone apps ${ }^{28}$ or smartwatch ${ }^{29}$ can, in real-time, observe personal health records and daily physical activities outside of the hospital, and web-based observational studies have been performed. Furthermore, nation-wide research is ongoing by corporations about the efficient emergency medical system operating method using artificial intelligence and big data, such as geographic, personal, meteorological, traffic data. ${ }^{30}$ Some university hospitals also provide their beds to corporations as open-bed-laboratory for artificial intelligence research to develop efficient medicine. ${ }^{31}$ These big trends that academia and corporations collaborate to do DL research will spur researchers to develop artificial intelligence-based efficient medicine.

In the future, after sufficient nation-wide, academicand corporation-initiated big study will be performed, by synchronizing a wide variety of medical information ${ }^{32,33}$ among the electronic medical records, personal smartphones, and smartwatches, as well as integrating the physical activities or meteorological conditions in real-time, the prediction of daily ambulance transport could be performed with much higher accuracy. This dreamlike prediction would solve the lack of medical resources in Japan by deploying the limited medical resources in the right amount and at the right time. Our study is preliminary and the first step to this dreamlike medicine.

\section{Limitation}

First, we used the data from only three years, and we did not perform external validation. Further studies with external validation using more data should be needed. Second, the meteorological data and ambulance transport dataset are based on the 24-hr calendar day period (0:00AM-11:59PM), but the work at the hospital begins at approximately 9:00AM, and it should be the start line to use prediction models practically. Third, we should have adjusted the ambulance transports by background age and population.

\section{Conclusion}

We investigated the associations between the meteorological and calendarial factors with ambulance transport. Similar to the previous reports, we could statistically make polynomial curves, but the $\mathrm{r}^{2} \mathrm{~s}$ were small. Besides, we preliminarily made DL-based prediction models for total daily ambulance transport more than 5 (median) or not, the presence of daily CPA transport, and that of daily trauma transport with only meteorological and calendarial variables. The models' accuracies were satisfactory.

To predict ambulance transport is needed to save the medical resources and to perform the efficient medical practice. In the future, by synchronizing a wide variety of medical information, among the electronic medical records, personal smartphones, and smartwatches, as well as integrating the physical activities or meteorological conditions in real-time, the DL-based prediction of ambulance transport would be done with much higher accuracy. This dreamlike prediction would solve the lack of medical resources in Japan by deploying the limited medical resources in the right amount and at the right time.

\section{Abbreviations}

ANN, artificial neural network; AUC, area under the curve; CPA, cardiopulmonary arrest; DL, deep learning; $\mathrm{Pa}$, daily mean atmospheric pressure; $\mathrm{r}^{2}$, determination coefficient; RH, daily mean relative humidity; ROC, receiver operating characteristic curve; THI, thermohydrological index; Tmax, daily highest ambient temperature; Tmax-mean, daily difference between the highest and lowest ambient temperature; Tmean, daily mean ambient temperature; Tmin, daily lowest ambient temperature.

\section{Ethics and Consent}

Approval of the research protocol: Kesennuma City Hospital Research Ethics Committee, Approval No. KHEC-6. Informed consent: waived and anonymized. Registration No. N/A. 


\section{Acknowledgments}

We are thankful for the staff in our hospital and the Fire Department Service in Kesennuma.

\section{Author Contributions}

All the authors have read the manuscript and have approved this submission. All authors made substantial contributions to conception and design, acquisition of data, or analysis and interpretation of data; took part in drafting the article or revising it critically for important intellectual content; agreed to submit to the current journal; gave final approval of the version to be published; and agree to be accountable for all aspects of the work. Especially, MK contributed to performing statistical analysis and making artificial intelligence models, and $\mathrm{NN}$, HO, and YK supervised our work.

\section{Funding}

There is no funding to report.

\section{Disclosure}

The authors report no conflicts of interest in this work or interest related to the manuscript.

\section{References}

1. Kadooka Y, Asai A, Enzo A, Okita T. Misuse of emergent healthcare in contemporary Japan. BMC Emerg Med. 2017;17:23. doi:10.1186/ s12873-017-0135-4

2. Ng CFS, Ueda K, Ono M, Nitta H, Takami A. Characterizing the effect of summer temperature on heatstroke-related emergency ambulance dispatches in the Kanto area of Japan. Int $J$ Biometeorol. 2014;58:941-948. doi:10.1007/s00484-013-0677-4

3. Miyatake N, Sakano N, Murakami S. The relation between ambulance transports stratified by heat stroke and air temperature in all 47 prefectures of Japan in August, 2009: ecological study. Environ Health Prev Med. 2012;17(1):77-80. doi:10.1007/s12199-011-0221-2

4. Kotani K, Ueda K, Seposo X, et al. Effects of high ambient temperature on ambulance dispatches in different age groups in Fukuoka, Japan. Glob Health Action. 2018;11(1):1437882. doi:10.1080/ 16549716.2018.1437882

5. Bando M, Miyatake N, Kataoka H, et al. Relationship between air temperature parameters and the number of deaths stratified by cause in Gifu prefecture, Japan. Healthcare. 2020;8(1):35. doi:10.3390/ healthcare 8010035

6. Mochimasu KD, Miyatake N, Tanaka N, Kinoshita H. Lower air temperature is associated with ambulance transports and death in Takamatsu area, Japan. Environ Health Prev Med. 2014;19 (4):253-257. doi:10.1007/s12199-014-0385-7

7. Kataoka H, Mochimasu KD, Katayama A, et al. The linkage among ambulance transports, death and climate parameters in Asahikawa City, Japan. Environ Health Prev Med. 2015;20(1):63-67. doi:10. 1007/s12199-014-0429-z

8. Owari Y, Miyatake N, Yamamoto Y, Kataoka H, Mochimasu KD. Relationship between air temperature and death in all 47 prefectures of Japan. Rom J Leg Med. 2016;24:61-70. doi:10.4323/rjlm.2016.61
9. Hayashi S, Noda T, Kubo S, et al. Variation in fracture risk by season and weather: a comprehensive analysis across age and fracture site using a National Database of Health Insurance Claims in Japan. Bone. 2019;120:512-518. doi:10.1016/j.bone.2018.12.014

10. Kamimura K, Yokoyama T, Yamagishi M, Yasutoshi F. Motor vehicle accident in snowy areas. Nippon Eiseigaku Zasshi Japanese J Hyg. 1966;21(5):350-355. doi:10.1265/jjh.21.350

11. Akioka H, Yufu K, Teshima Y, et al. Seasonal variations of weather conditions on acute myocardial infarction onset: oita AMI Registry. Heart Vessels. 2019;34(1):9-18. doi:10.1007/ s00380-018-1213-6

12. Ogata T, Kimura K, Minematsu K, Kazui S, Yamaguchi T. Variation in ischemic stroke frequency in Japan by season and by other variables. $J$ Neurol Sci. 2004;225(1-2):85-89. doi:10.1016/j. jns.2004.07.002

13. Shinkawa A, Ueda K, Hasuo Y, Kiyohara Y, Fujishima M. Seasonal variation in stroke incidence in Hisayama, Japan. Stroke. 1990;21 (9):1262-1267. doi:10.1161/01.STR.21.9.1262

14. Hui L, Ruan Y, Liang R, Liu X, Fan Z. Short-term effect of ambient temperature and the risk of stroke: a systematic review and meta-analysis. Int $J$ Environ Res Public Health. 2015;12 (8):9068-9088. doi:10.3390/ijerph120809068

15. Sony Network Communications. Prediction One. Available from: https://predictionone.sony.biz/. 2020. Accessed February 29, 2020.

16. Shibahara I, Osawa SI, Kon H, et al. Increase in the number of patients with seizures following the Great East-Japan Earthquake. Epilepsia. 2013;54(4):e49-e52. doi:10.1111/epi.12070

17. Peel MC, Finlayson BL, McMahon TA. Updated world map of the Köppen-Geiger climate classification. Hydrol Earth Syst Sci. 2007;11 (5):1633-1644. doi:10.5194/hess-11-1633-2007

18. Dick WF, Baskett PJ, Grande C, et al. "Recommendations for uniform reporting of data following major trauma-the Utstein style" (as of July 17, 1999). An international trauma anaesthesia and critical care society (ITACCS). Acta Anaesthesiol Belg. 2000;51(1):18-38.

19. Japan Meteorological Agency, Ministry of Land, Infrastructure, Transport and Tourism J. Japan Meteorological Agency Official Homepage. 2020. Available from: https://www.data.jma.go.jp/obd/ stats/etrn/index.php. Accessed March 8, 2020.

20. Sueda Y, Hosomi N, Tsunematsu M, et al. Effects of meteorological conditions on the risk of ischemic stroke events in patients treated with alteplase - HEWS-tPA. J Stroke Cerebrovasc Dis. 2015;24 (7):1500-1505. doi:10.1016/j.jstrokecerebrovasdis.2015.03.013

21. Ministry of Health, Labor and Welfare in Japan M. Current status and issues of the emergency medical system in Japan. 2017. Available from: https://www.mhlw.go.jp/content/10802000/000328610.pdf. Accessed March 14, 2020.

22. Ministry of Education, Culture, Sports, Science and Technology in Japan M. Publication of the "survey on the payment of doctors and dentists other than faculty members engaged in medical care at university hospitals. 2020. Available from: https://www.mext.go.jp/ a menu/koutou/iryou/1418468.htm. Accessed March 13, 2020.

23. Lin AX, Ho AFW, Cheong KH, et al. Leveraging machine learning techniques and engineering of multi-nature features for national daily regional ambulance demand prediction. Int $J$ Environ Res Public Health. 2020;17(11):4179. doi:10.3390/ijerph17114179

24. Setzler H, Saydam C, Park S. EMS call volume predictions: a comparative study. Comput Oper Res. 2009;36(6):1843-1851. doi:10.1016/j.cor.2008.05.010

25. Chen AY, Lu TY, Ma MHM, Sun WZ. Demand forecast using data analytics for the preallocation of ambulances. IEEE J Biomed Heal Informatics. 2016;20(4):1178-1187. doi:10.1109/JBHI.2015.2443799

26. Katsuki M, Kakizawa Y, Nishikawa A, Yamamoto Y, Uchiyama T. Easily created prediction model using deep learning software (Prediction One, Sony Network Communications Inc.) for subarachnoid hemorrhage outcomes from small dataset at admission. Surg Neurol Int. 2020;11:374. doi:10.25259/SNI_636_2020 
27. Katsuki M, Narita N, Matsumori Y, et al. Preliminary development of a deep learning-based automated primary headache diagnosis model using Japanese natural language processing of medical questionnaire. Surg Neurol Int. 2020;11:475. doi:10.25259/SNI

28. Yamamoto K, Takahashi T, Urasaki M, et al. Health observation app for COVID-19 symptom tracking integrated with personal health records: proof of concept and practical use study. JMIR mHealth uHealth. 2020;8(7):e19902. doi:10.2196/19902

29. Chae SH, Kim Y, Lee KS, Park HS. Development and clinical evaluation of a web-based upper limb home rehabilitation system using a smartwatch and machine learning model for chronic stroke survivors: prospective comparative study. JMIR mHealth uHealth. 2020;8(7):e17216. doi:10.2196/17216

30. Nippon Telegraph and Telephone Corporation Research and Development N. Research to optimize emergency medical system operations using artificial intelligence and big data. 2019. Available from: https://www.rd.ntt/research/AP99-330.html. Accessed December 23, 2020.
31. Tohoku University T. Japan's first hospital demonstration field for Problem-solving research and development -Tohoku University Hospital Smart Hospital Project -. 2019. Available from: https:// www.hosp.tohoku.ac.jp/wp-content/uploads/2019/12/bfb9a d537eb93285717b473288981563.pdf. Accessed January 20, 2021.

32. Fuse N, Sakurai-Yageta M, Katsuoka F, et al. Establishment of integrated biobank for precision medicine and personalized healthcare: the Tohoku Medical Megabank Project. JMA J. 2019;2 (2):113-122. doi:10.31662/jmaj.2019-0014

33. Yasuda J, Kinoshita K, Katsuoka F, et al. Genome analyses for the Tohoku Medical Megabank Project towards establishment of personalized healthcare. J Biochem. 2019;165(2):139-158. doi:10.1093/jb/ mvy096

\section{Publish your work in this journal}

The Open Access Emergency Medicine is an international, peerreviewed, open access journal publishing original research, reports, editorials, reviews and commentaries on all aspects of emergency medicine. The manuscript management system is completely online and includes a very quick and fair peer-review system, which is all easy to use. Visit http://www.dovepress.com/testimonials.php to read real quotes from published authors. 